\title{
Polymer and Colloid Chemistry in Switzerland
}

\author{
Christian Quellet*
}

\begin{abstract}
On the occasion of the creation of the new Polymers and Colloids Division of the Swiss Chemical Society, the author, formerly President of the Swiss Group of Colloid and Interface Science (1996-1999) and President of the Polymer Group of Switzerland (2004-2007), presents some aspects of the development of polymer and colloid chemistry in Switzerland in the last fifty years.
\end{abstract}

Keywords: Associations · History of science · PGS · Polymer and colloid chemistry

The year 2007 was marked by the creation of the new Polymers and Colloids division of the Swiss Chemical Society and, for many of us, this event is the culmination of almost a quarter of century of continuing effort to make macromolecular and 'soft matter' chemistry a recognized area within the Swiss chemical community. On this occasion, it is tempting to look back at the recent past and retrace the evolution of this important, but often ignored, aspect of our recent scientific history. ${ }^{[1]}$
${ }^{*}$ Correspondence: Dr. C. Quellet

Givaudan Schweiz AG

Ueberlandstrasse 138

$\mathrm{CH}-8600$ Dubendorf

Tel: +41448242424

Fax: +41448242926

E-mail: christian.quellet@givaudan.com
Polymers and colloids are found everywhere in nature and in daily life, and count among the most abundant chemicals that are found on the Earth after minerals, nitrogen, oxygen and water. Polymers are the building blocks of living organisms (cellulose, chitin, collagen), they govern the exchange of matter (membrane proteins) and even of information (DNA). The self-association of surfactants is responsible for the formation of cell membranes. A tremendous number of human-made commodities are built of plastics or coated with polymers. On the other hand, the common feature of blood, milk, paints, glues and ice-creams is their colloidal nature.

However, everybody who has read a general chemistry text book will hardly find more than one or two very general and poorly documented chapters about polymers and colloids; and very few people will be aware that wood or even a salad sauce are actually... chemicals. The problem and the beauty of polymer and colloid sciences is to be found in their truly multidisciplinary nature, involving such very diverse skills and knowledge of chemistry, physics, material sciences and engineering. This 'stateless' status might explain why, for decades, none of our established scientific societies, such as the Swiss Chemical Society, the Association of Swiss Chemists, or the Swiss Physical Society included polymers and colloids in their core activities. As a matter of fact, for more than a century, these materials have been seen as the dirty side of organic chemistry, while physicists were more than reluctant to handle such 'impure' or poorly defined systems. Even today, the presence of almost insoluble, gum-like, waxy or stone-hard residues in the bottom of an or- ganic chemist's reactors is the synonym of failure, not of an opportunity.

\section{The Pionieering Years}

In the second half of the last century, the focus of Swiss organic chemistry was definitively on stereochemistry and on the synthesis of natural substances, while spectroscopy and photochemistry were draining the efforts of physical chemists. The interest for polymers was limited in the chemical community. In a certain sense, the schism had already been initiated in 1920 by ETH lecturer Hermann Staudinger (1881-1965) with his postulate that polymers are, by essence, difficult to char-

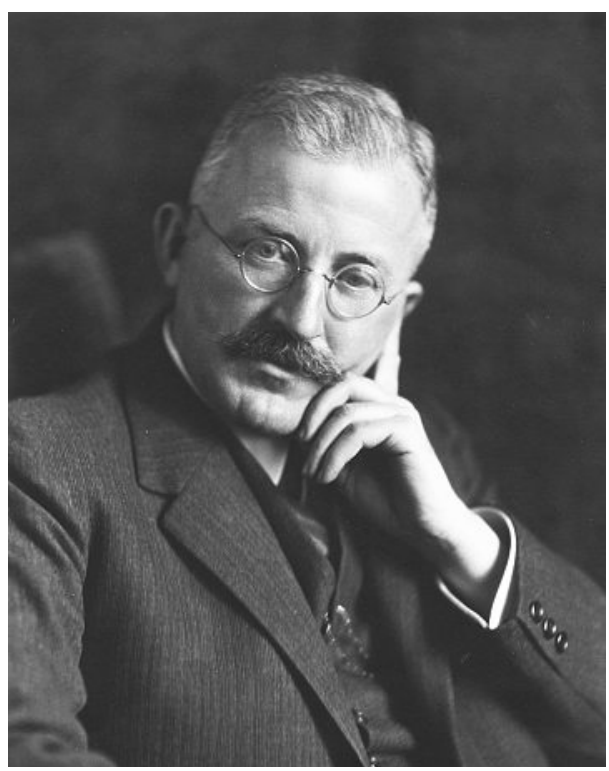

ETH professor Hermann Staudinger, the father of modern polymer science. Photograph: ETHBibliothek Zürich, Bildarchiv. 
acterize giant molecules ('macromolecules'), and not micellar, supramolecular complexes of small well-defined molecules. Quite paradoxically, Switzerland, which had hosted the father of macromolecular chemistry (Hermann Staudinger received the Nobel Prize in $1953^{[2]}$ ), and which has otherwise become a widely recognized leader in chemistry, was not inclined to promote polymer chemistry as an area deserving sustained academic attention. While one reason frequently used to explain the lack of interest for polymers was the absence of an established petroleum industry and especially of oil cracking plants in the country, the influence of the pharmaceutical industry on national scientific programs was certainly the determining factor. As a matter of fact, academic institutions and federal scientific authorities at that time did not develop polymer sciences to an extent comparable to that prevailing in countries like France, Germany, Italy, UK, Netherlands or Sweden, which had already a long tradition in polymer manufacturing and application.

The decisive change was initiated in 1966 under the pressure of the major Basel chemical companies who pleaded in favour of the creation of a chair of macromolecular chemistry at the ETH in Zurich (ETHZ), in order to take into account "the storming development of plastics (...) and their worldwide market, estimated at 60 billion Swiss francs in 1970".[3] Concomitantly, the Swiss mechanical and building industries recognized the importance of plastics ('Kunststoffe') in their applications and the need of experts in modern materials science. In 1968, Piero Pino (1921-1989), former professor of chemistry at the University of Pisa, was elected professor of macromolecular chemistry at ETHZ and Joachim Meissner to the chair of polymer physics in 1974 . The ETHZ Institute of Polymers was created in 1983 and then included in the Department of Materials, created in 1981.[4] Hence, in the 1980s, ETHZ was clearly taking the lead in Swiss polymer chemistry and physics. At the same time, however, a few research groups emerged throughout the country, such as the groups of Manfred Mutter (University of Basel, synthetic polypeptides), Markus Neuenschwander (University of Bern, conductive polymers), Albert Renken (EPFL, polymer reaction engineering), to name just a few chemists who moved away from the mainstream programs. Similarly, the technology of plastics continued to develop in engineering institutes and schools, such as EPFL (Hans-Heinig Kausch, fracture and self-healing) or HTL Brugg-Windisch (Wolfgang Kaiser, plastics engineering).

In these pioneering years, the major chemical companies together with the Association of Swiss Chemists developed their own international connections by organizing the series of so-called Interlaken Macromolecular Symposia starting in the

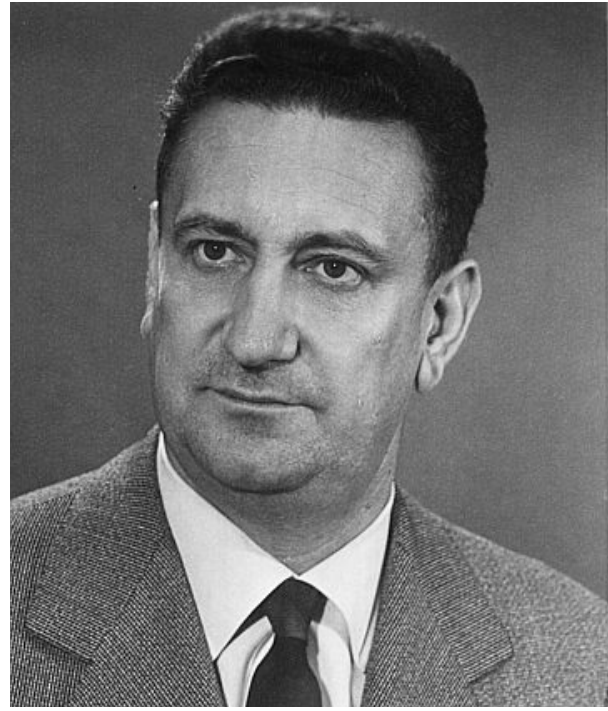

entists even more desirable. Discussions were also ongoing at the European level about bringing local polymer research activities under a common umbrella that was recognized in Brussels. The absence of any organization capable of representing the Swiss counterpart to other national ones was no longer acceptable. Again, the decisive input in this direction came from Zurich. Mid 1983, at the initiative of Piero Pino, an informal committee comprising representatives of industry and academic institutions was set up with the mission of creating the basis of a new polymer association. The composition of this committee ${ }^{[5]}$ appears today to be particularly interesting as it reveals, through the presence of Forbo-Giubasco SA, Brown Boveri, Landis \& Gyr, Viscosuisse, Sulzer, Huber \& Suhner, a strong focus on technical polymers and their industrial applications, and through Ciba Geigy AG and Sandoz AG, on polymer additives. In other words, the engineering and materials aspects of polymers had a clear priority over biopolymer and formulation aspects. The Polymer Group of Switzerland or Polymer Gruppe der Schweiz (PGS) was finally founded on September 4, 1984 in the Aula Maxima of ETH Zurich.

The audience was impressive, reflecting how strong the commitment was at that time to make such a platform happen. Its mission was to promote polymer science and technology in Switzerland, to foster contacts between the industry and the academic institutions through organizing meetings and symposia, to encourage interactions between different polymer disciplines and to cooperate with similar international organisations. In the early nineties, the PGS had up to 300 regular members and more than 100 sponsor members, including all major chemical companies of this country. In 1990, the subgroup, Rheology, primarily dedicated to the rheology of polymer melts and viscoelastic materials, was created under the impetus of Joachim Meissner. ${ }^{[6]}$ At the same time, under the impetus of leading academic and industrial representatives, ${ }^{[7]}$ continuing efforts were made to expand the scope of the PGS into emerging fields, such as functional polymers, biopolymers, supra-molecular assemblies and nanotechnologies. the ultimate recognition of polymer science, 15 years after Doi and Edwards for their contributions to polymer dynamics, and 30 years after Flory's fundamental work on polymer thermodynamics.

\section{The Polymer Group of Switzerland}

This context made the creation of a national organization specifically dedicated to the growing community of polymer sci-

\section{The Revival of Colloid Sciences}

The idea to include colloids as a new subgroup within the PGS was put forward in the early eighties by Pier Luigi Luisi, who was then in charge of the laboratory of supramolecular chemistry at ETH Zurich. The shape and scope of the Colloid Subgroup was defined and the group 
founded on May 5, 1992 under the name: 'Swiss Group of Colloid and Interface Sciences'. Again, it is worth having a look at the status of colloid and interface science prevailing at that time in Switzerland. The situation was not different from that prevailing for polymers a few decades earlier. Despite the set-up of intensive programs at the international level and the fact that Albert Einstein was living in Bern when he published his most influential articles on Brownian motion (1905) and on viscosity of suspensions (1906), the interest of Swiss scientific authorities for the colloid state remained limited for most of the twentieth century. As for polymers, chemists were generally considering "anything between the molecule and the material" as too dirty and undefined to be worth the effort. The activity was confined to a few loosely interconnected laboratories, such as the above-mentioned ETHZ group and the groups of Hans-Friedrich Eicke (University of Basel, microemulsions), Michael Grätzel (EPFL, optoelectronic at interfaces), Thomas Binkert and Jaro Ricka (University of Bern, physical methods), Jacques Buffle (University of Geneva, environmental chemistry) or Gerhard Schwartz (Biozentrum Basel, membranes). Furthermore, the diaspora of young emerging colloid scientists had limited chance to access substantial funding to be able to build up modern colloid science in Switzerland. This disinterest today appears astonishing when one considers the tremendous importance of colloids and colloidal phenomena in almost all areas of industry! Indeed, colloids play a

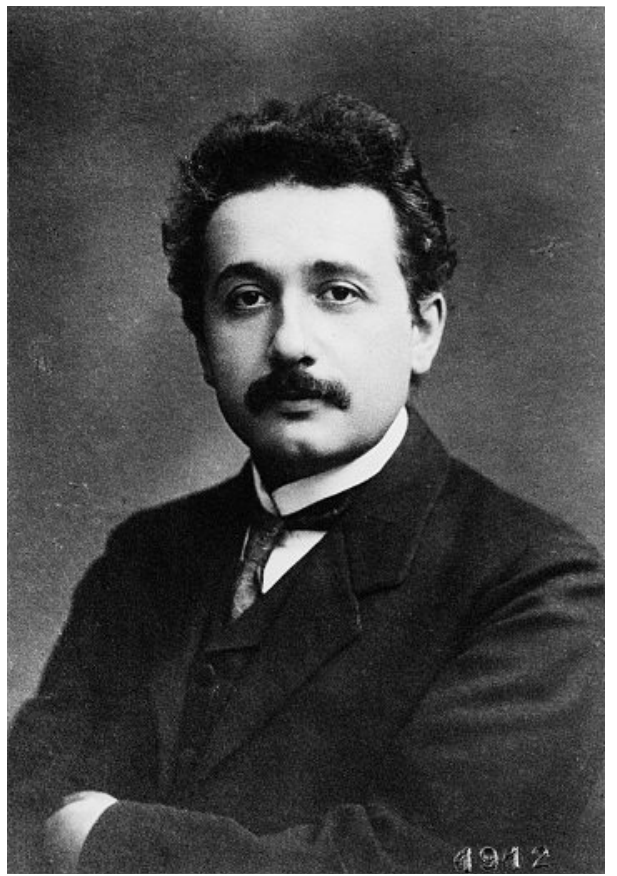

Albert Einstein in 1912, a few years after his major contributions to colloid science. Photograph: ETH-Bibliothek Zürich, Bildarchiv. central role in the texture of food, stability of cosmetics and pharmaceutical formulations, flow behaviour of paint, coatings and adhesives, sol-gel routes to ceramics, chemical transport in sediments or nutrient transport through the living organism.

The foundation of the Colloid Group was certainly a milestone in the recognition of the colloid community in our country. In 2000, the group had up to 100 members from both the industry and academic institutions and was strongly represented in almost all regions of Switzerland - many members of the group are now key actors of the Swiss colloid scene. On the other hand, the booming interest for nanosciences, and related national funding programs, has greatly contributed to the current consolidation of colloid resources in this country.

\section{Back to Chemistry}

Today, it is recognized that both polymer and colloid sciences are intimately connected and, together, cover a broad diversity of systems, from soft matter to hard resins and from highly functional supramolecular architectures to commodity plastics. Remarkably, this close connection between polymers and colloids was already addressed by Staudinger in his Nobel lecture of 1953 ! A common feature of both domains is their multidisciplinary nature, at the crossroads of physics, material science, technology, biology and, of course, chemistry. At the end of the day, however, chemistry remains the heart of polymers and colloids, as it determines the nature of their building blocks and thereby controls their ultimate properties. This simple fact, along with the opportunity to build up new synergies, has greatly driven the decision to merge the Polymer Group of Switzerland and the Colloid Group into a new division of the Swiss Chemical Society. This merger will certainly help to increase the audience and presence of the polymer and colloid communities at both national and international level, and contribute to reinforce the links between chemistry and material sciences and technologies.

Received: June 13, 2008

[1] Unfortunately, documents related to scientific history are generally scarce and valuable information, such as programs and handovers of symposia and events, difficult to find, if not lost. Most of the factual content of the present paper is based on the author's memory and personal notes and can only be fragmentary. The author apologizes for unintended omissions and any imprecision, and gratefully acknowledges the referees for their valuable comments.
[2] http://nobelprize.org.

[3] A. Westermann, 'Die Einrichtung einer Professur für Makromolekulare Chemie', undated web document, http://www. ethistory.ethz.ch.

[4] J. Meissner, 'The Founding of the Department', 2006, 2008; E. Freitag, 'History of the Department of Materials', undated web documents, http://www.mat. ethz.ch/about_us/history/founding.

[5] PGS Archives.

[6] The Rheology Group resigned from the PGS organization in 2006 to become independent under the name Swiss Group of Rheology.

[7] The Presidents of the PGS elected after Piero Pino came from both academic institutions: Robert Deschenaux (University of Neuchâtel), Wolfgang Kaiser (HTL Brugg-Windisch \& KATZ), Hans-Heinig Kausch (EPFL), Ulrich Suter (ETH); and industrial companies of that time: Roland Darms (CIBA), Ernesto Engel (Huber \& Suhner), Anton Demarmels (ABB), Rudolf Merz (Landy \& Gyr), Martin Roth (Huntsman) and the author of this paper. 